\title{
РЕАЛИЗАЦИЯ ЛИНГВОПРАГМАТИЧЕСКОГО ПОДХОДА К ОБУЧЕНИЮ ИНОСТРАННОМУ ЯЗЫКУ В ВУЗЕ
}

\section{THE IMPLEMENTATION \\ OF LINGUOPRAGMATIC APPROACH TO FOREIGN LANGUAGES EDUCATION IN HIGH SCHOOL}

\section{Pchelintseva \\ A. Chumakova \\ Ye. Arzhilovskaja}

Summary: The linguopragmatic approach is implemented in the methodology of foreign languages teaching to form a foreign language competence. The article outlines the main requirements that contribute to the implementation of the pragmatic aspect in ELT process. Those include the creation of problem situations close to reality, sociallyoriented, professionally-directed simulations and games, new active forms and techniques on the bases of modern digital technologies. The article raises the question of the formation of discourse skills for practicing communication. The results of using the linguopragmatic approach to ELT include an increase in motivation for learning and a significant increase in the quality of teaching and the formation of communicative foreign language competence among students of non-linguistic universities.

Keywords: the linguopragmatic approach, ELT process, pragmatic aspect, discourse skills, communicative foreign language competence.
Пчелинцева Ирина Геннадьевна

Д.п.н., профессор, Тюменский индустриальный университет

pchelintsevaig@tyuiu.ru

чумакова Анна Викторовна

К.п.н., доцент, Тюменский индустриальный университет chumakovaav@tyuiu.ru

Аржиловская Елена Ивановна

К.с.н., дочент, Тюменский индустриальный университет arzhilovskajaei@tyuiu.ru

Аннотация: Лингвопрагматический подход реализуется в методике обучения иностранному языку в целях формирования иноязычной компетенции. В статье обозначены основные требования, которые способствуют реализации прагматического аспекта в обучении. К таковым относятся создание проблемных ситуаций, близких к реальности, социально-ориентированные, профессионально-направленные симуляции и игры, новые активные направления и методические приемы с использованием современных цифровых технологий. В статье поднимается вопрос о формировании дискурсивного навыка для отработки навыков коммуникации. К результатам использования лингвопрагматического подхода к обучению иностранным языкам отнесено повышение мотивации к обучению и существенный рост качества обучения и формирования коммуникативной иноязычной компетенции у студентов неязыковых вузов.

Ключевые слова: лингвопрагматический подход, прагматический аспект, методика обучения иностранному языку, дискурсивный навык, коммуникативная иноязычная компетенция.

студента, что предполагает использование интерактивных способов обучения.

зей современного общества владение иностран-
ным языком стало одним из основных условий, которое обеспечивает конкурентоспособность личности на всех этапах её профессионального становления. Анализ существующей образовательной ситуации показал основные направления, которые активно внедряются в систему подготовки студентов в современных образовательных учреждениях:

- более глубокое осмысление образовательных ступеней как непрерывной цепочки образования, обеспечивающей преемственность обучения;

- компьютеризация и технологизация обучения, способствующие развитию интеллектуальной деятельности студентов и реализации принципов индивидуализации и дифференциации обучения;

- внедрение активных методов, форм и приемов обучения, основанные на включении в деятельность студентов элементы проблемности, научного поиска, самостоятельной работы;

- акцент на организации обучения как коллективной, совместной деятельности преподавателя и
Вышеизложенные направления не покажутся трюизмом, если принять во внимание, что реализация их в практике пока еще оставляет желать лучшего.

Анализируя эти направления в современной практике обучения иностранным языкам мы предполагаем, что их реализация возможна на основе включения лингвопрагматического подхода в образовательный процесс.

Современные исследователи во главе с А.М. Акопянц отмечают, что методика обучения продолжает опираться в своём развитии на традиционную лингвистику, тогда как подобный подход не поспевает за современным образом языка [1]. Всё больше отечественных и зарубежных исследователей видят решение сложившейся проблемы в применении лингвопрагматических методов обучения.

В последние десятилетия лингвопрагматическая на- 
правленность стала актуальна не только для лингвистики, но и для методики обучения иностранным языкам: ключевой целью обучения становится способность обучающихся применить умения на практике, и, вместе с тем, сам процесс обучения организован на основе постоянной деятельности.

Как справедливо отмечает А.М. Акопянц, современные требования и государственные стандарты требуют отказаться от привычного абстрактного изучения отдельных разделов языка, а целью образования становится не просто дать представления и знания о грамматике, фонетике и синтаксисе иностранного языка, а научить применять имеющиеся навыки в ситуации реального общения [2].

Лингвопрагматический подход применяют в процессе обучения каждому виду речевой деятельности и различным аспектам языка.

В процессе практической реализации идеи формирования иноязычной компетенции студентов технического вуза мы выделили существенные требования к основным методическим моментам, которые обеспечивают прагматическую составляющую процесса обучения. Обучение коммуникативной компетенции проходит в ситуациях общения, которые должны быть реальными, проблемными. Такие ситуации следует тщательно продумывать, «подсматривать» в реальной жизни и переносить на занятие полностью или фрагментарно. Такие ситуации стимулируют студентов использовать иностранный язык в качестве способа решения той коммуникативной задачи, которую ставит именно ситуация. Кроме того, в реальной ситуации решаются металингвистические задачи (например, выразить самому или вызвать у собеседника то или иное эмоциональное состояние), а это уже говорит о навыках выбора речевых средств в соответствии своим целям и задачам, или стратегической компетенции в рамках коммуникативной компетенции. Реальная ситуация побуждает студентов использовать свой социокультурный опыт и знания, поскольку часто бывает непредсказуемой, непланируемой и меняющейся. Поэтому такая ситуация всегда нова, интересна и актуальна для студента. Можно с уверенностью сказать, что подбор «живых» ситуаций общения мотивирует студентов, а это очень важный аспект успешности обучения иностранным языкам. Прежде всего прагматика призывает использовать социальноориентированные, профессионально-направленные симуляции и игры, основанные на реальных или прогнозируемых для студента сценариях. Например, студентам может быть предложена ситуация: «вы опоздали на занятие, в коридоре института встретили своего сокурсника. Расскажите о причинах опоздания». Кроме того, преподаватель должен предлагать ситуации, основываясь на интересах своих студентов, если кто-то из них занима- ется футболом, можно предложить ему смоделировать коммуникативную ситуацию с тренером или товарищами по команде, тому, кто любит читать можно предложить рассказать о своём любимом авторе или книге. Прагматика призывает отказываться от бессмысленных диалогов, направленных лишь на отработку лексикограмматических конструкций, считая это первым шагом к демотивации студентов. Кроме того, в данном контексте также актуальны задания описательного характера, к примеру, можно предложить студентам описать сюжет или смоделировать определенную ситуацию по фото или картинке. Прагматика подчёркивает также важность спонтанных языковых ситуаций: учитель может задать любой вопрос, развить дискуссию, создав тем самым новый коммуникативный контекст.

В современных условиях полного или частичного дистанционного образования, мы хотим предложить в качестве одного из вариантов реализации лингвопрагматического подхода свое видение достаточно распространенного метода тандемного обучения с использованием современных средств обучения. В основе тандем-технологии лежит самостоятельное знакомство и овладение иностранным языком и культурой двумя партнерами, являющимися носителями разных языков и работающих в паре. В качестве партнеров-носителей иностранного языка выступали иностранные студенты. Овладение языком партнера происходит посредством виртуального общения, направленного на знакомство с партнером, культурой его страны, сопровождающийся процессом получения интересной информации. Тандем-технология представляет интенсивный подход к изучению английского языка, так как предусматривает непосредственное погружение в языковую среду в ходе общения с его носителем.

Для того, чтобы студенты могли успешно общаться с иноязычными собеседниками, необходимо обеспечить лингвопрагматическую составляющую в образовательном процессе посредством познания чужого образа жизни и поведения, расширения собственной картины мира за счет приобщения к картине мира изучаемого языка. Определенную трудность составляет выбор темы беседы. Приоритетными оказывались далекие от профессиональной сферы деятельности темы, однако вызывающие неподдельный интерес именно к культурной составляющей: музыка, знаменитости, погода и климат, компьютерные игры, спорт и пр. Использование тандемтехнологий показало перспективность данного метода работы: были достигнуты хорошие результаты студентами, которые принимали участие в тандем-занятиях. Однако, следует отметить ограниченную доступность данного метода и сложность для студентов, не имеющих достаточных навыков общения на иностранном языке.

Наш опыт показал эффективность включения линг- 
вопрагматики в процесс обучения иностранному языку на основе групповых форм работы на основе активного применения дискурса. Дискурсивные навыки отрабатываются на материале ситуаций, с которыми студент сталкивается каждый день: домашние обязанности, студенческая жизнь, учеба, отношения со сверстниками и т.д. Дискурс вводится ради живой коммуникации, а не отработки, скажем, грамматического времени и включает новые формы общения (мини-дискуссия, круглый стол). А групповые задания были нацелены на отработку навыков коммуникации и ответственности, обеспечивая динамичный ход занятия, использование большого количества визуализации, в том числе с помощью цифровых и компьютерных средств, работу в группах, парах, выполнение индивидуальных проектов с использованием ИКТ и интернет-ресурсов, видео, программ.

В сети интернет представлен целый комплекс источников для онлайн тренировки звукопроизношения, чтения, говорения, видеохостинги содержат банки видеозанятий, а также видеофильмы и мультфильмы, адаптированные для изучения определённых языковых явлений. Программы серии Lingvo дают возможность создавать собственные картотеки новых слов и затем тренировать их. Сервисы, подобные Quizlet, Duolingvo также предлагают разнообразить процесс отработки новой лексики, содержат звуковые файлы, дают возможность тренировать сразу два иностранных языка. Стоит отметить и вспомогательные сервисы при создании так называемых mindmaps. Такие приложения как Popplet предлагают не просто оформить диаграмму лексических или понятийных связей, но также сделать это красиво, добавив картинки, с привлечением интернет-ссылок на видео материал. Такой сервис пригодится не только студентам для создания глоссария к тексту или банка лексики по определённой теме, но и для преподавателя, который может оформить план занятия в виде Popplet-карты. Практическое применение и интеграция компьютерных и интернет-ресурсов в процесс обучения иностранному языку в вузе не противоречит, а, наоборот, делает современным лингвопрагматический подход.

В целом, реализуя лингвопрагматический подход к обучению иностранному языку, преподаватели получают убедительные результаты в виде повышения мотивации студентов к изучению иностранного языка, что, в свою очередь оказывает непосредственное влияние на эффективность процесса обучения и качество получаемых навыков и компетенций.

Лингвопрагматика в очередной раз доказала свою состоятельность как перспективное направление практической и научной деятельности многих ученых и практиков, работающих над повышением качества преподавания иностранных языков в вузе и формированием высокого уровня коммуникативной компетенции студентов технического вуза.

\section{ЛИТЕРАТУРА}

1. Акопянц, А.М. Прагматика и лингводидактика / А.М. Акопянц. — Ростов-на-Дону: Изд-во ЮФу, 2008. — 137 с.

2. Акопянц, А.М. Основополагающие принципы прагмалингво-дидактики / А.М. Акопянц // Известия ВГлу. — 2008. — № 9 (33). — C. 230-236

3. Истоки, проблемы и категории прагматики / Арутюнова, Д.Н, Падучева, В.Е. // Новое в зарубежной лингвистике. — 1988. — № Вып.16 Лингвистическая прагматика. - C. 3-47.

4. Мосалова, А.И. Прагматизация процесса обучению иноязычному профессиональному общению студентов экономического профиля / А.И. Мосалова. // Материалы международной научно-методической конференции. Гуманитарная образовательная среда технического вуза. — Санкт-Петербургский политехнический университет Петра Великого , 2016. - C. 211-213.

5. Hymes, D. On Communicative Competence / D. Hymes. — Direct text // Sociolinguistics. — Harmondsworth : Penguin, 1972. — P. 269-293

6. Таюрская, Н.П. Иноязычная коммуникативная компетенция: отечественный и зарубежный опыт / Н.П. Таюрская. // Гуманитарный вектор. — 2015. — № 1 (41). - C. 83-87.

( П Пчелинцева Ирина Геннадьевна (pchelintsevaig@tyuiu.ru), Чумакова Анна Bикторовна (chumakovaav@tyuiu.ru), Аржиловская Елена Ивановна (arzhilovskajaei@tyuiu.ru).

Журнал «Современная наука: актуальные проблемы теории и практики» 